Article

\title{
Design of Novel Haptens and Development of Monoclonal Antibody-Based Immunoassays for the Simultaneous Detection of Tylosin and Tilmicosin in Milk and Water Samples
}

\author{
Jian-Xin Huang ${ }^{1}$, Chan-Yuan Yao ${ }^{1}$, Jin-Yi Yang ${ }^{1}$, Zhen-Feng Li ${ }^{2}$, Fan He ${ }^{1}$, Yuan-Xin Tian ${ }^{3, *}$, \\ Hong Wang ${ }^{1}$, Zhen-Lin $\mathrm{Xu}^{1}{ }^{1}$ and Yu-Dong Shen ${ }^{1, *}$ \\ 1 College of Food Science, Guangdong Provincial Key Laboratory of Food Quality and Safety, South China \\ Agricultural University, Guangzhou 510642, China; bi@stu.scau.edu.cn (J.-X.H.); ciel32o@163.com (C.-Y.Y.); \\ yjy361@163.com (J.-Y.Y.); snowywhite@163.com (F.H.); gzwhongd@163.com (H.W.); jallent@163.com (Z.-L.X.) \\ 2 Department of Entomology and Nematology and UCD Comprehensive Cancer Center, University of \\ California Davis, Davis, CA 95616, USA; fzhli@ucdavis.edu \\ 3 Guangdong Provincial Key Laboratory of New Drug Screening, School of Pharmaceutical Sciences, \\ Southern Medical University, Guangzhou 510515, China \\ * Correspondence: tyx523@163.com (Y.-X.T.); shenyudong@scau.edu.cn (Y.-D.S.); \\ Tel.: +86-20-627-894-16 (Y.-X.T.); +86-20-852-834-48 (Y.-D.S.)
}

Received: 21 October 2019; Accepted: 19 November 2019; Published: 23 November 2019

\begin{abstract}
In this work, a monoclonal antibody-based indirect competitive enzyme-linked immunosorbent assay (icELISA) was established to detect tylosin and tilmicosin in milk and water samples. A sensitive and specific monoclonal antibody was prepared by rational designed hapten, which was achieved by directly oxidizing the aldehyde group on the side chain of tylosin to the carboxyl group. Under the optimized conditions, the linear range of icELISA for tylosin and tilmicosin were 1.3 to $17.7 \mathrm{ng} / \mathrm{mL}$ and 2.0 to $47.4 \mathrm{ng} / \mathrm{mL}$, with half-maximal inhibition concentration $\left(\mathrm{IC}_{50}\right)$ values of 4.7 and $9.6 \mathrm{ng} / \mathrm{mL}$, respectively. The cross-reactivity with other analogues of icELISA was less than $0.1 \%$. The average recoveries of icELISA for tylosin and tilmicosin ranged from $76.4 \%$ to $109.5 \%$ in milk and water samples. Besides, the detection results of icELISA showed good correlations with HPLC-MS/MS. The proposed icELISA was satisfied for rapid and specific screening of tylosin and tilmicosin residues in milk and water samples.
\end{abstract}

Keywords: hapten; monoclonal antibody; immunoassay; tylosin; tilmicosin

\section{Introduction}

Tylosin is a macrolide antibiotic obtained from the culture fluid of Streptomyces fradiae and has a wide antibacterial spectrum against gram-positive organisms, selected gram-negative organisms, as well as mycoplasma, Rickettsia, and Chlamydia [1,2]. Tilmicosin is the semisynthetic derivative of tylosin (Figure 1), which has a similar antibacterial spectrum to tylosin [3]. Furthermore, tilmicosin has a better antibiosis effect than tylosin against gram-negative organisms, mycoplasma, pasteurella, and can be used to control mycoplasma avian disease and mastitis of lactating cows [4-6]. Due to effective antibiotic properties, tylosin and tilmicosin are widely applied to treat bacterial infection in various animals, including beef cattle swine and poultry [4,7]. Besides, tylosin and tilmicosin can also promote animal growth and increase feed utilization as a feeding additive $[8,9]$. Tylosin and tilmicosin have a low metabolic rate after administration, and their residues are widely distributed in the body fluids and tissues of livestock $[7,10]$. In addition, it was reported that tylosin and tilmicosin residues 
could also be tested in environmental samples, such as water [11,12]. Therefore, excessive use of these antibiotics could result their residues existing in animal tissues or the environment, and intake with prolonged low doses of antibiotics can bring potential risk to human health, such as human allergy and resistance [13-15]. Thus, maximum residue limits (MRLs) for tylosin and tilmicosin have been established as 0.05 to $1.5 \mathrm{mg} / \mathrm{kg}$ in food samples in China [16], and banned as feed additives in the European Union [17].

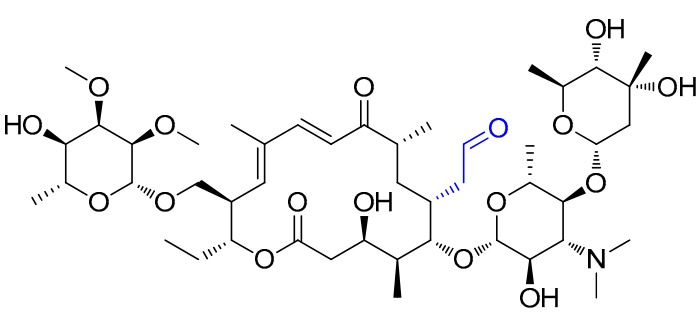

Tylosin(TYL)

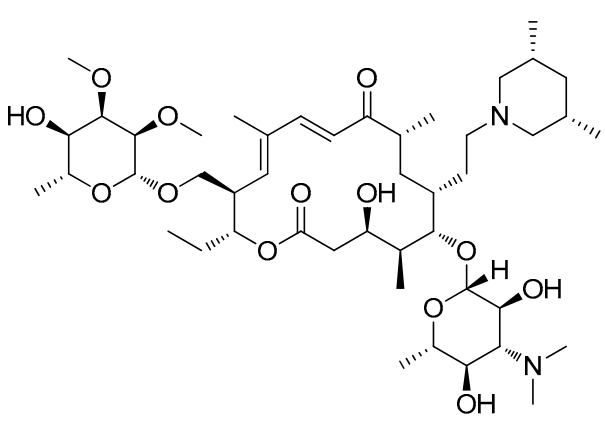

Tilmicosin(TMC)

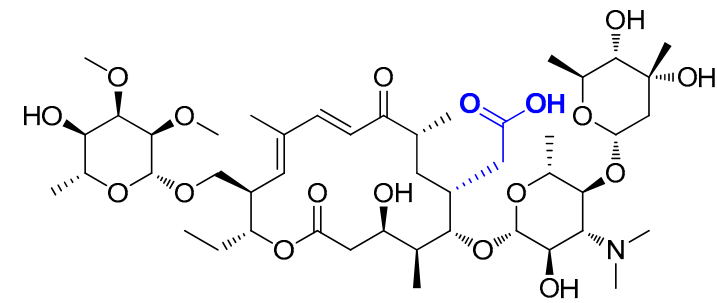

TYL-CHO

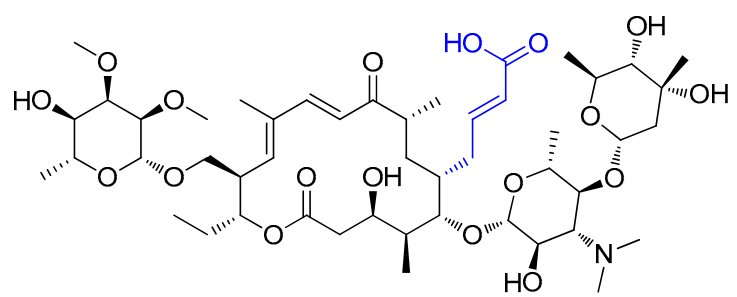

TYL-MA

Figure 1. The structures of tylosin (TYL), tilmicosin (TMC), and haptens (TYL-CHO and TYL-MA). The spacer arm of two haptens labeled in blue.

Currently, methods for simultaneous detection of tylosin and tilmicosin mainly include high-performance liquid chromatography (HPLC), high performance liquid chromatography coupled with tandem mass spectrometry (HPLC-MS/MS), and other large-scale chromatographic methods [18-20]. These large-scale equipment methods are highly sensitive and accurate, but are expensive, time-consuming, have low sample throughput, and are inconvenient for detection in the field. As an alternative, due to its advantages of being fast, easy to use, low cost, and portable, the most practical immunoassay, primarily enzyme-linked immunosorbent assay (ELISA), has been widely developed and used to rapidly monitor various pesticides and veterinary drugs in food and environment samples with high-throughput sample, and plays a vital role in field detection [21-24]. It is well known that antibodies are the core reagents for the development of immunoassay methods. To date, the antibodies used in the simultaneous detection of tylosin and tilmicosin are mainly obtained by immunization with Shiff base arm hapten derived from carbonyl amino condensation and some of these reported immunoassays are also sensitive and accurate [2,25-28]. Thus, our first attempt was to use the reported Shiff base hapten strategy, but this failed to obtain an antibody against tylosin and tilmicosin because of the poor and unstable immune response. We speculated that the lone spacer arm attached to the tylosin molecules could change the original conformation of tylosin, and the carbon-nitrogen double bond arm in the reported Shiff base hapten could be instable for long-term maintenance of the immune response in animals [29]. So, as an alternative attempt, novel hapten strategies for mimicking tylosin to the maximum extent were proposed for steadily inducing an antibody against tylosin and cross-reacted with tilmicosin. Finally, the icELISA method was developed for the simultaneous detection of tylosin and tilmicosin in milk and water samples in this study. 


\section{Materials and Methods}

\subsection{Materials and Instruments}

Tylosin, tilmicosin, bovine serum albumin (BSA), spiramycin, roxithromycin, avermectin, N-Hydroxysuccinimide (NHS), dicyclohexylcarbodiimide (DCC), ovalbumin (OVA), HAT Media Supplement $(50 \times)$, complete and incomplete Freund's adjuvant, goat anti-mouse Immunoglobulin G (IgG) horseradish peroxidase conjugate (HRP-IgG), and Tween-20 were purchased from Sigma-Aldrich (St. Louis, MO, USA). Acetylspramycin, furadantin, enrofloxacin, pyridine, and triethylamine were purchased from Shanghai Civic Chemical Technology Co., Ltd. (Shanghai, China). Nitrofural, erythromycin, azithromycin, pefloxacin, and propanedioic acid were purchased from Shanghai Macklin Biochemical Co., Ltd. Fetal calf serum, Pierce Rapid Isotyping Kits-Mouse, poly-ethylene glycol (PEG-1450), and RPMI Medium 1640 basic (1×) were purchased from Thermo Fisher Scientific Co., Ltd. (Waltham, MA, USA). Protein-G Resin was purchased from TransGen Biotech. Inc. (Beijing, China). Other chemicals were purchased from Guangzhou chemical reagent Co., Ltd. Female BALB/c mice were purchased from Guangdong Medical Laboratory Animal Center (Guangzhou, China). Phosphate solution (PBS, 0.01 M at pH 7.4): $8.5 \mathrm{~g} / \mathrm{L} \mathrm{NaCl}, 2.9 \mathrm{~g} / \mathrm{L} \mathrm{Na}{ }_{2} \mathrm{HPO}_{4} \cdot 12 \mathrm{H}_{2} \mathrm{O}, 0.2 \mathrm{~g} / \mathrm{L} \mathrm{KH}_{2} \mathrm{PO}_{4}$, $0.2 \mathrm{~g} / \mathrm{L} \mathrm{KCl}$ ). Dilution solution (0.01 M PBST at pH 7.4): 0.1\% Tween-20 in 0.01 M PBS. Coating buffer: $0.1 \mathrm{M}$ carbonate buffer at $\mathrm{pH}$ 9.6. Blocking buffer: 0.05\% Tween-20 and 5\% skim milk powder in $0.01 \mathrm{M}$ PBS. Washing solution: $8.5 \mathrm{~g} / \mathrm{L} \mathrm{NaCl}, 2.9 \mathrm{~g} / \mathrm{L} \mathrm{Na}{ }_{2} \mathrm{HPO}_{4} \cdot 12 \mathrm{H}_{2} \mathrm{O}$, and $0.01 \%$ Tween-20. Stop solution: $20 \%$ sulfuric acid. Nano Drop 2000C ultra-violet spectrophotometer (Thermo Scientific, Waltham, MA, USA), DEM-3 automatic plate washer (Top Analytical Instruments Co., Ltd., Beijing, China), AB SCIEX 5500 triple quadrupole mass spectrometer (AB SCIEX, Redwood City, CA, USA), and Hypersil GOLD-C18 (2.1 mm $\times 100 \mathrm{~mm}, 1.9 \mu \mathrm{M}$, Thermo Scientific, Waltham, MA, USA) were used in this study.

\subsection{Synthesis of Haptens and Antigens}

Synthesis of TYL-CHO. The hapten TYL-CHO was obtained by using our own previously reported methods [30]. Tylosin ( $1 \mathrm{~g}, 1.09 \mathrm{mmol})$ was dissolved in $80 \mathrm{~mL}$ of 1-Butanol: $\mathrm{H}_{2} \mathrm{O}(5: 3, v / v)$ at $0{ }^{\circ} \mathrm{C}$. $\mathrm{NaH}_{2} \mathrm{PO}_{4}(0.62 \mathrm{~g}, 5.17 \mathrm{mmol}), 1 \mathrm{~mL}$ of dimethyl sulfoxide, and $\mathrm{NaClO}_{2}(0.2 \mathrm{mg}, 2.21 \mathrm{mmol})$ were added in cold solution sequentially and refluxed for $30 \mathrm{~min}$. The mixture was extracted by ethyl acetate/brine, and then the organic layer was dried over anhydrous $\mathrm{Na}_{2} \mathrm{SO}_{4}$. After removal of solvent under reduced pressure, the crude mixture was purified by column chromatography $(\mathrm{MeOH}$ :Trichloromethane $=1: 10$, $v / v)$, and hapten TYL-CHO was obtained (Figure S1A) and confirmed by ESI-MS ( $\mathrm{m} / \mathrm{z}$, positive, 932.5494 $\left.[\mathrm{M}+\mathrm{H}]^{+}\right)$.

Synthesis of TYL-MA. Tylosin $(1 \mathrm{~g}, 1.09 \mathrm{mmol})$ and propanedioic acid $(0.1 \mathrm{~g}, 0.96 \mathrm{mmol})$ were dissolved in $10 \mathrm{~mL}$ of pyridine. In total, $1 \mathrm{~mL}$ of triethylamine was added in solution and refluxed under nitrogen for $2 \mathrm{~h}$. The mixture was added in $2 \mathrm{M}$ hydrochloric acid aqueous solution and cooled until room temperature. After filtration, the deposit was washed by water and recrystallized by ethanol aqueous solution. The crude mixture was purified by column chromatography (MeOH:Trichloromethane $=1: 10$, $v / v)$, and TYL-MA was obtained (Figure S1B) and confirmed by ESI-MS ( $\mathrm{m} / \mathrm{z}$, positive, 958.5473 $\left.[\mathrm{M}+\mathrm{H}]^{+}\right)$.

The two haptens were conjugated with BSA for use as immunizing conjugates and OVA as coating conjugates according to the modified procedure in [31]. Hapten (0.1 mmol), DCC (0.2 mmol), and NHS $(0.2 \mathrm{mmol})$ were dissolved in $0.5 \mathrm{~mL}$ of DMF and stirred at $4{ }^{\circ} \mathrm{C}$ overnight. In total, $15 \mathrm{mg}$ of BSA or OVA were dissolved in $5 \mathrm{~mL}$ of $0.1 \mathrm{M}$ PBS $(\mathrm{pH}=7.4)$. Next, $250 \mu \mathrm{L}$ of the hapten reaction mixture were added to the carrier protein solution slowly and stirred at $4{ }^{\circ} \mathrm{C}$ for $12 \mathrm{~h}$. After being dialyzed in PBS at $4{ }^{\circ} \mathrm{C}$ for 3 days, the mixture was stored at $-20^{\circ} \mathrm{C}$ until use. The structure of the conjugate was confirmed by UV-vis spectral. 


\subsection{Immunization and Monoclonal Antibodies}

Each female BALB/c mouse (7-8 weeks old) was immunized with immunogen that was prepared by emulsification of immunogen $(1 \mathrm{mg} / \mathrm{mL}, 100 \mu \mathrm{L})$ and Freund's adjuvant $(100 \mu \mathrm{L})$. The immunizing conjugates were injected subcutaneously on the back and abdomen of each mouse. Complete adjuvant was used for the first injection. After three weeks, the incomplete adjuvant was used for the subsequent injections in every two weeks. One week after the fourth injection, mice sera were collected from their tail tip and evaluated by icELISA and the mice with the best response was chose for the generation of hybridomas by cell fusion.

Myeloma cells Sp2/0 were fused with the spleen cells of immunized mice at a ratio of 5:1 according to the modified procedure of [32]. Hybridomas from wells with a positive response by icELISA were selected. After cell culture, the hybridomas were injected into mice intraperitoneally and the ascites were collected after 8 to 10 days. The ascites was purified by column chromatography of Protein-G Resin. The purified monoclonal antibodies (mAbs) were detected as the concentration of the antiserum by NanoDrop 2000c and stored at $-20^{\circ} \mathrm{C}$ until use.

\section{4. icELISA Protocol}

An icELISA was used to evaluate the binding ability and specificity of sera or monoclonal antibody $(\mathrm{mAb})$. Serial concentrations of the coating antigens in coating buffer were added in the 96-well polystyrene ELISA plates with $100 \mu \mathrm{L}$ per wells and incubated at $37^{\circ} \mathrm{C}$ overnight. Then, the wells were washed two times with washing buffer and the uncoated sites were blocked for $3 \mathrm{~h}$ at $37^{\circ} \mathrm{C}$. Finally, the plates were dried at $37^{\circ} \mathrm{C}$ for $1 \mathrm{~h}$ and stored at $4{ }^{\circ} \mathrm{C}$ until use. Briefly, $50 \mu \mathrm{L}$ of varying concentration sera or $\mathrm{mAb}$ in $0.01 \mathrm{M} \mathrm{PBST}$ and $50 \mu \mathrm{L}$ of varying concentration of tylosin standard were incubated in plates at $37^{\circ} \mathrm{C}$ for $40 \mathrm{~min}$. Then, the plates were washed five times and $100 \mu \mathrm{L}$ of HRP-anti mouse IgG were added in PBST (1:5000) at $37^{\circ} \mathrm{C}$ for $30 \mathrm{~min}$. After being washed five times, $100 \mu \mathrm{L}$ of substrate solution were added in the plates and incubated at $37^{\circ} \mathrm{C}$ for $10 \mathrm{~min}$. Finally, by the addition of stop solution, with $50 \mu \mathrm{L}$ added to each well, the optical density was measured at $450 \mathrm{~nm}$ by Multiskan MK3. The percentage inhibition of sera or $\mathrm{mAb}$ binding ability was expressed as follows: Titer means the dilution of antiserum with an absorbance at $450 \mathrm{~nm}$ of about 1.0 to 1.5, with a high inhibition (inhibition $=\left[\left(\mathrm{B}-\mathrm{B}_{0}\right) / \mathrm{B}\right] \times 100 \%$, $\mathrm{B}$ means the absorbance without a competitor and $\mathrm{B}_{0}$ means the absorbance with a competitor).

\subsection{Optimization of icELISA Condition}

To improve the sensitivity of icELISA, several parameters were optimized, including the concentration of antibody, coating antigens and HRP-IgG, working buffer (ionic strength, $\mathrm{pH}$ value and the concentration of Tween-20), and reaction time. According to the dose-response curves, the maximum absorbance value $\left(\mathrm{A}_{\max }\right)$ and half maximal inhibitory concentration $\left(\mathrm{IC}_{50}\right)$ were calculated. The optical conditions were confirmed by $\mathrm{A}_{\max }, \mathrm{A}_{\max } / \mathrm{IC}_{50}$, and $\mathrm{IC}_{50}$. A condition with a higher value of $\mathrm{A}_{\max } / \mathrm{IC}_{50}$ and lower value of $\mathrm{IC}_{50}$ were selected to use in the assay. After the optimization of condition, serial dilutions of tylosin or tilmicosin were added in the working buffer as the competitor to construct the standard curve by sigmoidal curve fitting in origin pro 9.0 software (Originlab Corp., Northampton, MA, USA).

\subsection{Preparation and Elimination of Matrix Effect in Samples for icELISA}

All the tylosin- and tilmicosin-free samples were confirmed by HPLC-MS/MS and pretreated using the method as follows. For icELISA: $1 \mathrm{~mL}$ of milk was dissolved in $20 \mu \mathrm{L}$ of $\mathrm{H}_{2} \mathrm{SO}_{4}(2 \mathrm{~mol} / \mathrm{L}$, to remove the fat and protein) and stirred. Then, the mixture was centrifuged at $4000 \mathrm{rpm}$ for $5 \mathrm{~min}$ to obtain the supernatant. After being filtered by $0.22 \mu \mathrm{m}$ of membrane, the supernatant was diluted 2-, 5-, and 10-fold with PBST. Water sample: $1 \mathrm{~mL}$ of tap water, drinking water, and environmental water (come from a pond in Guangzhou) were filtered by $0.22 \mu \mathrm{m}$ of membrane. The tap water, drinking 
water, and environmental water were diluted 0-, 1-, 2-, 3-, and 5-fold with PBST. Serial dilutions of tylosin or tilmicosin were added in the serial dilution of sample buffers as the competitor to test using icELISA, and compared with the standard curves or visual result constructed by PBST under the optimization condition. The best dilution to eliminate the matrix effect was confirmed by comparing the calibration curves of the diluted sample solution and PBST.

\subsection{Comparison of icELISA with HPLC-MS/MS}

Tylosin or tilmicosin in different concentrations were spiked in the milk and water samples. According to the modified procedure of the icELISA as above, all the spiked samples were subjected by icELISA to test the recovery, and validated by HPLC-MS/MS by referring to the China National Standard [33] with a column of Hypersil GOLD-C18 $(2.1 \mathrm{~mm} \times 100 \mathrm{~mm}, 1.9 \mu \mathrm{m})$. The flow rate of the HPLC-MS/MS method was $0.5 \mathrm{~mL} / \mathrm{min}$, with a $30{ }^{\circ} \mathrm{C}$ column temperature and $10-\mu \mathrm{L}$ sample size. The mobile phases were $0.1 \%$ of formic acid (A) and methanol (B). The gradient elution: 0-25 min, 30-95\% of $\mathrm{B} ; 2.5-3 \mathrm{~min}, 95 \%$ of $\mathrm{B}$; $3-3.1 \mathrm{~min}, 95 \%-30 \%$ of $\mathrm{B}$; and $3.1-5 \mathrm{~min}, 30 \%$ of $\mathrm{B}$.

Linear regression between the method of icELISA and HPLC-MS/MS was used to check the consistency of these methods. To testify the verification of this icELISA method, the actual samples were selected randomly and analyzed by icELISA and HPLC-MS/MS. In total, 40 blind samples were purchased or provided from local supermarkets, Guangdong institute for food inspection, ponds, laboratory, and household tap in Guangzhou.

\subsection{Molecular Simulation}

Molecule modelling was performed by Schrodinger software package. The chemical structures of haptens, TYL, and TMC were constructed by 2D sketcher. Their geometries were optimized by OPLS3 force field implemented in Schrodinger, Maestro 11.1. Then, they were aligned by the quick align method. The electrostatic potential of selected difference atoms were colored in the surface. The color ramp was red_white_blue.

\section{Results and Discussion}

\subsection{Design and Screening of the Haptens}

High-quality antibodies are key for immunoassays, ultimately depending on rational hapten design [34]. Generally, a rational-designed hapten should be highly overlapped with the target molecules in a three-dimensional structure and bring stable immunogenicity to induce an immune response. Besides, monoclonal antibody has a more widespread application than polyclonal antibody for its high specificity and good repeatability according to our ongoing and in-depth research on the development of various immunoassay methods [35-37]. Based on our previous studies on polyclonal antibody against tylosin [30], we think that the new trend of antibody production of TYL and TMC should be characterized in terms of sensitivity and specificity, so we attempted to use different hapten strategies to immunize BALB/c mice for the preparation and screening of a high-quality monoclonal antibody. It was reported that more similar the characteristics of a hapten derivative are to the target, such as size, shape (geometry) and electronic properties, the more likely specific antibodies will be produced [38,39]. Moreover, it is also suggested that a short semi-rigid unsaturated double bond structure is generally good for the production of desired antibodies [40-42]. Based on these ideas, haptens with short spacer arms or unsaturated double bond arms were designed and the similarity between drugs and haptens was analyzed by molecular simulation. As shown in Figure 1, the spacer of hapten TYL-CHO contained a one-carbon-length carboxyl group, while hapten TYL-MA had a semi-rigid unsaturated spacer that was two carbon atoms longer. The results showed that hapten TYL-CHO gave the most effective specific immune response under the conditions of homology coating and the hapten TYL-MA gave no immune response against tylosin and tilmicosin (Table 1). The difference of the haptens, TYL, and TMC are shown in Figure 2. It is obvious that the hapten TYL-CHO 
(green) was highly similar to TYL (gray), while the hapten TYL-MA (blue) was quite different from TYL (Figure 2A-a,A-b). The long-chain carboxyl group with a carbon-carbon double bond affected the conformation of the macrocycle, which led to poor alignment with TYL. Furthermore, their electrostatic potential also displayed a remarkable difference (Figure 2B). The hapten TYL-MA is more negative than TYL (red area). Besides, the negative area of hapten TYL-MA was far from the macrocycle, probably responsible for the poor specific immune responses against TYL. Combining the immune results with structure analysis, we speculated that TYL-CHO maintained the spatial structure and electronic properties of tylosin so that the molecular structure of tylosin during immunization was exposed and stimulated the production of stable and specific antibodies efficiently. In addition, the hapten TYL-CHO also showed a high inhibition for TMC (Table 1). The spatial structure of TYL was different on TMC, but they had similar electronic properties (Figure 2B-d), with the same overlapped side-chain structure (Figure 2A-c, the red arrow point to the overlapping group). The overlapped side-chain structure was far away from the derivatized group of hapten, so the side-chain structure was considered as one of the key binding sites for the antibody and caused the high cross-reactivity $(49.0 \%$, Table 2) between TYL and TMC. In summary, it was an efficient strategy for target-derived hapten to be designed rationally through structure simulation, and further confirmed that the well-mimicked hapten TYL-CHO had stable immunogenicity to induce an antibody against tylosin in mice (Table 1).

Table 1. Titer and specificity of antiserum.

\begin{tabular}{|c|c|c|c|c|c|c|}
\hline \multirow{2}{*}{$\begin{array}{c}\text { Immunogen } \\
\text { Coating } \\
\text { Antigens }\end{array}$} & \multicolumn{3}{|c|}{ TYL-CHO-BSA } & \multicolumn{3}{|c|}{ TYL-MA-BSA } \\
\hline & Titer $^{a}\left(10^{3}\right)$ & $\begin{array}{c}\text { Inhibition } \\
\text { of TYL }(\%)\end{array}$ & $\begin{array}{l}\text { Inhibition } \\
\text { of TMC (\%) }\end{array}$ & Titer $\left(10^{3}\right)$ & $\begin{array}{l}\text { Inhibition } \\
\text { of TYL (\%) }\end{array}$ & $\begin{array}{c}\text { Inhibition } \\
\text { of TMC (\%) }\end{array}$ \\
\hline TYL-CHO-OVA & 16 & 89 & 78 & 0 & 0 & 0 \\
\hline TYL-MA-OVA & 0 & 0 & 0 & 0 & 0 & 0 \\
\hline
\end{tabular}

${ }^{\mathrm{a}}$ Titer means the dilution of antiserum with an absorbance at $450 \mathrm{~nm}$ of about $1.0-1.5{ }^{\mathrm{b}}$ Inhibition $=\left[\left(\mathrm{B}-\mathrm{B}_{0}\right) / \mathrm{B}\right] \times$ $100 \%$, under $1 \mu \mathrm{g} / \mathrm{mL}$ of competitor.

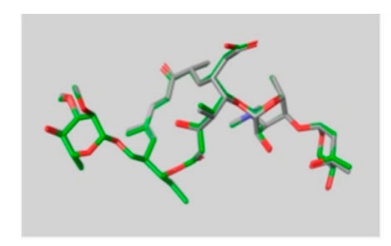

a. TYL (gray) and TYL-CHO (green)

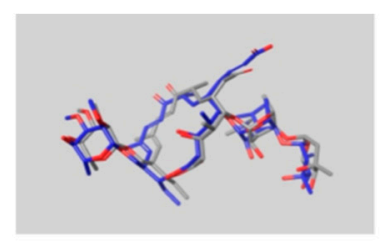

b. TYL (gray) and TYL-MA (blue)

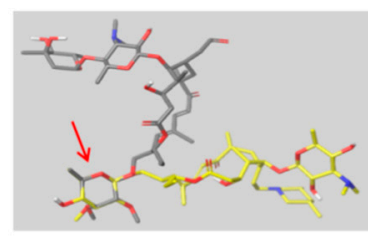

c. TMC(yellow) and TYL(gray)

(A)

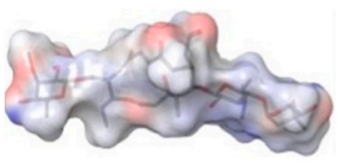

a. TYL

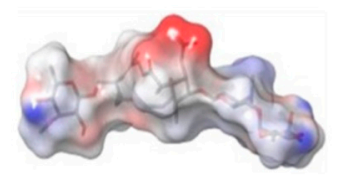

b. TYL-CHO

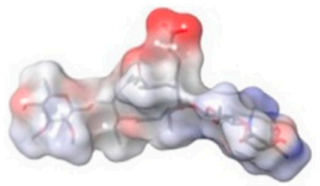

c. TYL-MA

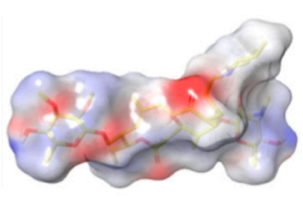

d. TMC

(B)

Figure 2. The alignment and electrostatic potential isosurfaces of haptens and target. (A) The structural alignment view, the red arrow point to the overlapping group between TYL and TMC; (B) The electrostatic potential isosurfaces, the blue areas indicate positive potential, the white areas indicate neutral potential, and the red areas indicate negative potential. 
Table 2. Cross-reactivity (CR) of macrolides antibiotics or related compounds in the icELISA.

\begin{tabular}{|c|c|c|c|}
\hline \multirow{2}{*}{ Compound } & \multirow{2}{*}{ Structure } & \multicolumn{2}{|c|}{ icELISA } \\
\hline & & $\mathrm{IC}_{50}(\mathrm{ng} / \mathrm{mL})$ & $C R *(\%)$ \\
\hline Tylosin & & 4.7 & 100 \\
\hline Tilmicosin & & 9.6 & 49.0 \\
\hline Erythromycin & & $>2000$ & $<0.1$ \\
\hline Roxithromycin & & $>2000$ & $<0.1$ \\
\hline Spiramycin & & $>2000$ & $<0.1$ \\
\hline Acetylspiramycin & & $>2000$ & $<0.1$ \\
\hline Abamectin & & $>2000$ & $<0.1$ \\
\hline Azithromycin & & $>2000$ & $<0.1$ \\
\hline Enrofloxacin & & $>2000$ & $<0.1$ \\
\hline Pefloxacin & & $>2000$ & $<0.1$ \\
\hline
\end{tabular}

* The values of CR were calculated by using the following equation: $\mathrm{CR}(\%)=\left[\mathrm{IC}_{50}\right.$ (melatonin, $\mathrm{mg} / \mathrm{mL}$ or $\mathrm{ng} / \mathrm{mL}) / \mathrm{IC}_{50}$ (cross-reactant, $\mathrm{mg} / \mathrm{mL}$ or $\mathrm{ng} / \mathrm{mL}$ ) $] \times 100 \%$. 


\subsection{Preparation and Characterization of Monoclonal Antibodies}

According to the immune results (Table 1), the TYL-CHO immunized mice with the highest titer and drug inhibition were selected for cell fusion. The mice spleen cells were fused with SP2/0 myeloma cells by the addition of ploy-ethylene glycol (PEG-1450) at a ratio of 5:1, then feeder cells were added in the cell mixture, and cultured in HAT medium for selection cultivation in a $\mathrm{CO}_{2}$ incubator. As fused hybridomas were increased, complete medium was used for cultivation, and the culture supernatant from each well were tested by icELISA. The hybridoma cells with strong positive response were sub-cloned three to four times. At last, four isolated hybridoma cells with a strong positive response against tylosin were selected and obtained as ascites from mice. The monoclonal antibodies were purified from ascites and determined by icELISA (Table 3). Of the four mAbs, L02 showed the best sensitivity to tylosin and cross-reacted with tilmicosin so that mAb L02 was selected for the rest of this study. Furthermore, the isotype of mAb L02 belonged to the IgG2b subtype that was tested by a commercial rapid isotyping kit (Figure S5).

Table 3. Characterization of mAbs against tylosin and cross-reaction with tilmicosin.

\begin{tabular}{ccccc}
\hline mAbs & Titer $\left(\mathbf{1 0}^{\mathbf{3}}\right)$ & $\begin{array}{c}\text { IC }_{\mathbf{5 0}} \\
\text { (ng/mL, Tylosin) }\end{array}$ & $\begin{array}{c}\text { IC }_{\mathbf{5 0}} \\
\text { (ng/mL, Tilmicosin) }\end{array}$ & $\begin{array}{c}\text { Cross-React with } \\
\text { Tilmicosin (\%) }\end{array}$ \\
\hline L01 & 1.6 & 6.2 & 16.1 & 38.5 \\
L02 & 1.6 & 5.0 & 8.5 & 58.8 \\
L03 & 1.6 & 5.2 & 9.2 & 56.4 \\
L04 & 1.6 & 5.9 & 21.5 & 26.9 \\
\hline
\end{tabular}

The mAbs were diluted 1:4000 in PBST $(0.01 \mathrm{~mol} / \mathrm{L}, \mathrm{pH} 7.4)$ with $0.11 \mu \mathrm{g} / \mathrm{mL}$ of coating antigen.

\subsection{The Standard Curve for icELISA}

Due to the immunoassay being an equilibrium binding reaction, it required a suitable dose of antibody, antigen, secondary antibody, and an appropriate buffer system [43]. The $\mathrm{pH}$ of the buffer could directly influence the sensitivity of the assay, and surfactant, such as Tween-20, could increase the hydrophilicity of the standards $[43,44]$. In this study, the concentration of antibody and antigen were determined by chessboard titration (Table S1). The optimum icELISA conditions were determined as follows (Figure S4): The antibody (L02) was diluted 1:16000 $(0.0625 \mu \mathrm{g} / \mathrm{mL})$ in PBST $(0.01 \mathrm{~mol} / \mathrm{mL}, 0.1 \%$ of Tween-20, pH 7.4) with $0.11 \mu \mathrm{g} / \mathrm{mL}$ of coating antigen. The HRP-IgG was diluted 1:5000 in $0.01 \mathrm{M}$ PBST and its reaction time with antibody was $30 \mathrm{~min}$. The standard curves of tylosin and tilmicosin were constructed under these conditions (Figure 3). The $\mathrm{IC}_{50}$ value of icELISA for tylosin and tilmicosin were 4.7 and $9.6 \mathrm{ng} / \mathrm{mL}$, respectively. The linear range $\left(\mathrm{IC}_{20}-\mathrm{IC}_{80}\right)$ was 1.3 to $17.7 \mathrm{ng} / \mathrm{mL}$ for tylosin and the one for tilmicosin was 2.0 to $47.4 \mathrm{ng} / \mathrm{mL}$. In short, the novel designed hapten TYL-CHO could induce a high sensitivity antibody and be applied for icELISA after optimization.

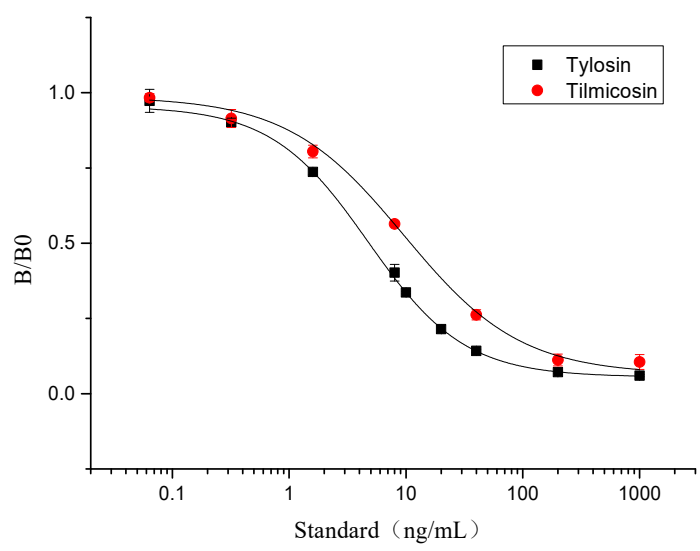

Figure 3. The icELISA standard curves of tylosin and tilmicosin. 


\subsection{Specificity of icELISA}

The cross-reactivity (CR) of monoclonal antibody L02 with nine macrolides antibiotics or related compounds is summarized in Table 2. The results demonstrated the antibody had cross-reactivities of $49.0 \%$ (icELISA) with tilmicosin, and extremely low cross-reactivities $(<0.01 \%)$ with other macrolides antibiotics and functional compounds, which confirmed that the monoclonal antibody (L02) could detect tylosin and tilmicosin simultaneously with high specificity, confirming the effectiveness of the rationally designed hapten.

\subsection{Elimination of Matrix Effect in Samples of icELISA}

The matrix of samples influenced the results of icELISA. The milk contains complex matrix compounds, such as proteins and fats, and the water samples contain invisible impurities and lack ions like sodium and potassium in the buffer system [45]. To eliminate the matrix effect in icELISA (Figure 4), the milk was diluted 1:10 in 0.01 M PBST. The tap water and drinking water were diluted 1:2 in 0.01 M PBST and environmental water was diluted 1:2 in 0.01 M PBST. As a result, this icELISA method could accomplish detection after a simple sample pretreatment.
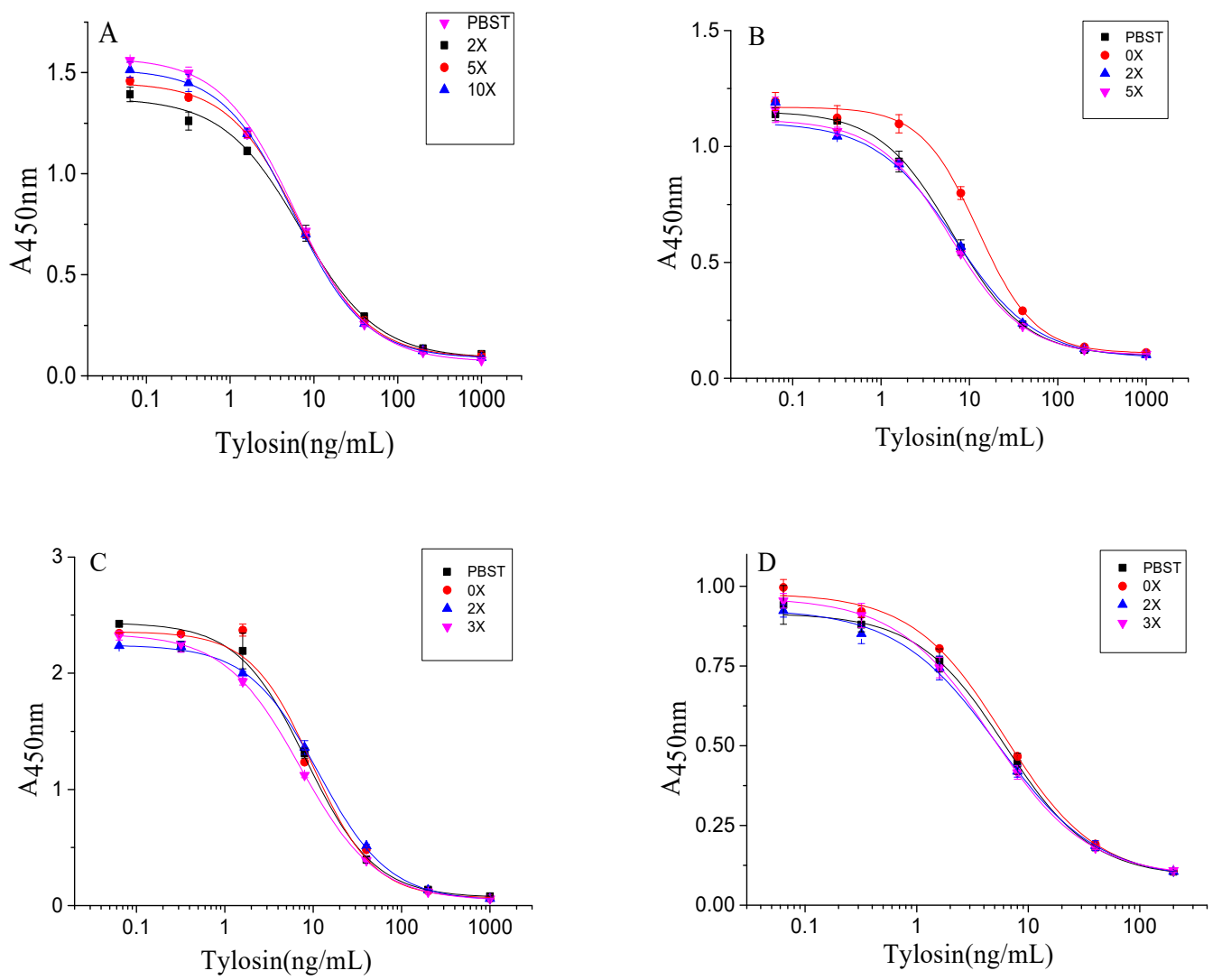

Figure 4. Matrix effect of the samples. environmental water).

((A) milk; (B) drinking water; (C) tap water; (D)

\subsection{Test in Spiked Samples and Real Positive Sample}

To evaluate the reliability of these results, all tylosin- and tilmicosin-free samples were confirmed by HPLC-MS/MS. Serial concentrations of tylosin and tilmicosin were spiked in the samples and detected the recoveries and coefficient of variance (CV) by icELISA and HPLC-MS/MS, respectively. As illustrated in Table 4, the recoveries of tylosin and tilmicosin were $76.4 \%$ to $109.5 \%$ for icELISA with CVs less than 15\%. Comparison of the results of icELISA and HPLC-MS/MS methods using linear regression analysis (Figure S7) showed there were good correlations between the two methods $\left(R^{2}=0.93\right)$, revealing the good accuracy of icELISA. In addition, there were 11 positive samples in 40 
real blind samples, which were confirmed by HPLC-MS/MS, and the analysis of real positive samples by icELISA also had good consistence with the analysis of HPLC-MS/MS (Table 5). In general, this icELISA could be applied for the detection of tylosin and tilmicosin simultaneously in real milk and water samples with high accuracy.

Table 4. Recoveries of tylosin-spiked and tilmicosin-spiked testing by icELISA and HPLC-MS/MS $(n=3)^{\mathrm{a}}$.

\begin{tabular}{|c|c|c|c|c|c|c|c|c|}
\hline \multirow[b]{2}{*}{ Samples } & \multirow[b]{2}{*}{ Spiked } & \multirow[b]{2}{*}{$\begin{array}{c}\text { Spiked } \\
\text { level } \\
(\mathrm{ng} / \mathrm{mL})\end{array}$} & \multicolumn{3}{|c|}{ icELISA } & \multicolumn{3}{|c|}{ HPLC-MS/MS } \\
\hline & & & $\begin{array}{c}\text { Measured } \\
(\mathrm{ng} / \mathrm{mL}) \\
\left(\text { mean } \pm \mathrm{SD}^{\mathrm{b}}\right)\end{array}$ & $\begin{array}{c}\text { Recoveries } \\
\text { (\%) }\end{array}$ & $\begin{array}{l}\text { CV } \\
(\%)\end{array}$ & $\begin{array}{c}\text { Measured } \\
(\mathrm{ng} / \mathrm{mL}) \\
(\mathrm{mean} \pm \mathrm{SD})\end{array}$ & $\begin{array}{c}\text { Recoveries } \\
\text { (\%) }\end{array}$ & $\begin{array}{l}\text { CV } \\
(\%)\end{array}$ \\
\hline \multirow{5}{*}{ Milk } & \multirow{3}{*}{ Tylosin } & 25 & $21.6 \pm 1.6$ & 86.4 & 7.4 & $20.16 \pm 0.41$ & 80.6 & 2.0 \\
\hline & & 50 & $41.8 \pm 6.0$ & 83.5 & 14.4 & $34.15 \pm 2.67$ & 68.3 & 7.8 \\
\hline & & 100 & $88.4 \pm 5.4$ & 88.4 & 6.1 & $78.61 \pm 0.71$ & 78.6 & 0.9 \\
\hline & \multirow[t]{2}{*}{ Tilmicosin } & 50 & $54.8 \pm 2.0$ & 109.5 & 3.6 & $55.05 \pm 0.71$ & 110.1 & 1.3 \\
\hline & & 100 & $83.0 \pm 3.5$ & 83.0 & 4.2 & $114.35 \pm 2.66$ & 114.4 & 2.3 \\
\hline \multirow{3}{*}{$\begin{array}{l}\text { Drinking } \\
\text { water }\end{array}$} & \multirow{3}{*}{ Tylosin } & 5 & $4.6 \pm 0.2$ & 92.2 & 4.3 & $3.61 \pm 0.41$ & 72.1 & 11.3 \\
\hline & & 10 & $7.6 \pm 0.2$ & 76.4 & 2.6 & $6.78 \pm 0.91$ & 67.8 & 13.4 \\
\hline & & 20 & $19.8 \pm 0.6$ & 99.2 & 3.0 & $14.52 \pm 1.18$ & 72.6 & 8.2 \\
\hline \multirow{5}{*}{ Tap water } & \multirow[t]{2}{*}{ Tylosin } & 10 & $8.3 \pm 0.3$ & 82.8 & 3.6 & $11.04 \pm 0.72$ & 110.4 & 6.6 \\
\hline & & 20 & $17.7 \pm 0.7$ & 88.2 & 4.0 & $22.85 \pm 0.18$ & 114.3 & 0.8 \\
\hline & \multirow{3}{*}{ Tilmicosin } & 5 & $4.2 \pm 0.3$ & 84.5 & 7.1 & $3.21 \pm 0.14$ & 64.3 & 4.3 \\
\hline & & 10 & $8.0 \pm 1.1$ & 80.0 & 13.8 & $6.65 \pm 0.21$ & 66.5 & 3.2 \\
\hline & & 20 & $18.8 \pm 2.1$ & 94.0 & 11.2 & $14.66 \pm 0.45$ & 73.3 & 3.1 \\
\hline \multirow{5}{*}{$\begin{array}{c}\text { Environmental } \\
\text { water }\end{array}$} & \multirow{3}{*}{ Tylosin } & 5 & $3.9 \pm 0.1$ & 77.2 & 2.6 & $4.29 \pm 0.13$ & 85.9 & 3.0 \\
\hline & & 10 & $8.8 \pm 0.3$ & 87.9 & 3.4 & $9.57 \pm 0.68$ & 95.7 & 7.1 \\
\hline & & 20 & $17.0 \pm 0.2$ & 85.1 & 1.2 & $18.37 \pm 1.36$ & 91.8 & 7.4 \\
\hline & \multirow[b]{2}{*}{ Tilmicosin } & 5 & $5.1 \pm 0.1$ & 101.7 & 2.0 & $3.24 \pm 0.13$ & 64.9 & 4.1 \\
\hline & & 10 & $7.9 \pm 0.1$ & 79.2 & 1.3 & $8.10 \pm 0.30$ & 81.0 & 3.7 \\
\hline
\end{tabular}

${ }^{\mathrm{a}}$ The spiked positive samples were tested per concentration by icELISA and HPLC-MS/MS. ${ }^{\mathrm{b}}$ Standard deviation.

Table 5. The detection amount of real positive samples $(n=3)^{\text {a }}$.

\begin{tabular}{|c|c|c|c|c|}
\hline \multirow[t]{2}{*}{ Sample } & \multirow[t]{2}{*}{ Number } & \multirow{2}{*}{$\begin{array}{c}\text { icELISA }\left(\mathrm{ng} / \mathrm{mL}^{2}\right) \\
\left(\text { mean }^{\mathrm{s}} \mathrm{SD}^{\mathrm{b}}\right) \\
\text { TYL/TMC }\end{array}$} & \multicolumn{2}{|c|}{$\begin{array}{l}\text { HPLC-MS/MS (ng/mL) } \\
\text { (mean } \pm \text { SD) }\end{array}$} \\
\hline & & & TYL & TMC \\
\hline \multirow{3}{*}{ Milk } & 1 & $17.9 \pm 0.9$ & $18.86 \pm 0.86$ & $\mathrm{ND}^{\mathrm{c}}$ \\
\hline & 2 & $17.7 \pm 0.4$ & $20.58 \pm 1.06$ & $\mathrm{ND}^{\mathrm{c}}$ \\
\hline & 3 & $9.4 \pm 0.9$ & $9.21 \pm 0.07$ & $\mathrm{ND}^{\mathrm{c}}$ \\
\hline \multirow{8}{*}{$\begin{array}{l}\text { Environmental } \\
\text { water }\end{array}$} & 4 & $0.5 \pm 0.1$ & $\mathrm{ND}^{\mathrm{c}}$ & $1.35 \pm 0.15$ \\
\hline & 5 & $0.7 \pm 0.1$ & $\mathrm{ND}^{\mathrm{c}}$ & $1.84 \pm 0.16$ \\
\hline & 6 & $0.9 \pm 0.1$ & $\mathrm{ND}^{\mathrm{c}}$ & $1.83 \pm 0.05$ \\
\hline & 7 & $1.2 \pm 0.1$ & $0.11 \pm 0.01$ & $3.18 \pm 0.09$ \\
\hline & 8 & $8.3 \pm 1.1$ & $10.04 \pm 0.23$ & $\mathrm{ND}^{\mathrm{c}}$ \\
\hline & 9 & $6.2 \pm 0.5$ & $7.24 \pm 0.42$ & $\mathrm{ND}^{\mathrm{c}}$ \\
\hline & 10 & $4.6 \pm 0.1$ & $4.93 \pm 0.13$ & $2.27 \pm 0.07$ \\
\hline & 11 & $18.1 \pm 0.6$ & $20.38 \pm 0.61$ & $\mathrm{ND}^{\mathrm{c}}$ \\
\hline
\end{tabular}

a The positive samples were tested by icELISA and HPLC-MS/MS. ${ }^{\mathrm{b}}$ Standard deviation. ${ }^{\mathrm{c}}$ ND: Not detected.

\section{Conclusions}

Based on a new rational hapten design strategy instead of traditional shiff base approach for tylosin and tilmicosin, a sensitive and effective antibody with stable immunogenicity was obtained 
in this study. After optimization, the icELISA for tylosin and tilmicosin was developed with high sensitivity and specificity. These developed assays were appraised by the cross-reactivity and recovery and validated by the HPLC-MS/MS results. In summary, this icELISA method was satisfactory for screening a large number of milk and water samples rapidly and could be applied for the detection of tylosin and tilmicosin simultaneously to meet different testing requirements.

Supplementary Materials: The following are available online at http://www.mdpi.com/2218-273X/9/12/770/s1, Figure S1: The synthesis route of haptens, Figure S2: The full scan mass spectra of haptens, Figure S3: The UV-vis spectral data of conjugates, hapten and proteins, Figure S4: Optimization of icELISA working condition, Figure S5: The isotype of mAb L02, Figure S6: Mass spectra of mixture standard of tylosin and tilmicosin, Figure S7: The linear regression analysis of between icELISA with HPLC-MS/MS, Table S1: The result of chessboard method for icELISA.

Author Contributions: Conceptualization, J.-X.H., C.-Y.Y. and Y.-D.S.; Methodology, J.-X.H. and C.-Y.Y.; Resources, J.-Y.Y. and Z.-L.X.; Writing-Original Draft Preparation, J.-X.H.; Writing-Review \& Editing, F.H. and Z.-F.L.; Supervision, Y.-D.S., H.W. and Y.-X.T.; Project Administration, Y.-D.S. All authors reviewed and approved the final submission.

Funding: This work was supported by the National Key Research and Development of China (2018YFC1602904), the National Natural Science Foundation of China (31871887), the Science and Technology Planning Project of Guangzhou (201704020082), the Key Scientific Research Projects of Guangdong Provincial Universities and Colleges (2018KZDXM011), the Guangdong Provincial Natural Science Foundation (2018B030314005) and the Science and Technology Planning Project of the Guangxi (2017AB47020), the Graduate Student Overseas Study Program of South China Agricultural University(2019LHPY003).

Conflicts of Interest: The authors declare no conflict of interest.

Ethical Approval: This article does not contain any studies with human subjects. All animal experiments that described in the present study were performed in the animal center of South China Agricultural University, following all institutional and national guidelines for the care and use of laboratory animals.

\section{References}

1. Vicca, J.; Maes, D.; Jonker, L.; De Kruif, A.; Haesebrouck, F. Efficacy of in-feed medication with tylosin for the treatment and control of Mycoplasma hyopneumoniae infections. Vet. Rec. 2005, 156, 606-610. [CrossRef] [PubMed]

2. Song, Y.; Song, S.; Liu, L.; Kuang, H.; Guo, L.; Xu, C. Simultaneous detection of tylosin and tilmicosin in honey using a novel immunoassay and immunochromatographic strip based on an innovative hapten. Food Agric. Immunol. 2016, 27, 314-328. [CrossRef]

3. Wei, S.; Le, T.; Chen, Y.; Xu, J.; He, H.; Niu, X.; Luo, J. Time-resolved fluoroimmunoassay for quantitative determination of tylosin and tilmicosin in edible animal tissues. Chin. Sci. Bull. 2013, 58, 1838-1842. [CrossRef]

4. Jordan, F.T.W.; Forrester, C.A.; Hodge, A.; Reeve-Johnson, L.G. The comparison of an aqueous preparation of tilmicosin with tylosin in the treatment of Mycoplasma gallisepticum infection of turkey poults. Avian Dis. 1999, 43, 521-525. [CrossRef]

5. Li, H.S.; Zhang, J.Y.; Zhou, X.Z.; Li, J.Y.; Li, J.S.; Miao, X.L.; Zhang, Z.F. Comparison of antibacterial effect of tilmicosin with tylosin on some commonly pathogenic bacteria of domestic animals. Prog. Vet. Med. 2006, 27, 94-96. [CrossRef]

6. Bicer, E.; Ozdemir, S. Voltammetric and spectroscopic studies on the interaction of tilmicosin with bovine serum albumin at different pHs. J. Electroanal. Chem. 2011, 657, 128-134. [CrossRef]

7. Arsic, B.; Barber, J.; Cikos, A.; Mladenovic, M.; Stankovic, N.; Novak, P. 16-membered macrolide antibiotics: A review. Int. J. Antimicrob. Agents 2017, 51, 283-298. [CrossRef]

8. Jones, P.W.; Tarrant, M.E. The effect of various factors on the efficacy of tylosin as a growth promoter in clinically healthy pigs. Anim. Prod. 2010, 34, 115-121. [CrossRef]

9. Cusack, P.M.V. Effect of mass medication with antibiotics at feedlot entry on the health and growth rate of cattle destined for the Australian domestic market. Aust. Vet. J. 2004, 82, 154-156. [CrossRef]

10. Avci, T.; Elmas, M. Milk and blood pharmacokinetics of tylosin and tilmicosin following parenteral administrations to cows. Sci. World J. 2014, 2014, 869096. [CrossRef] 
11. Sarmah, A.K.; Meyer, M.T.; Boxall, A.B.A. A global perspective on the use, sales, exposure pathways, occurrence, fate and effects of veterinary antibiotics (VAs) in the environment. Chemosphere 2006, 65, 725-759. [CrossRef] [PubMed]

12. Wang, X.; Guo, R.; Ma, B.; Liao, X.; Wu, Y. Excretion of sulfamethazine, chlortetracycline, tylosin and their main metabolites in pig manure. Chin. J. Vet. Sci. 2014, 34, 269-274. [CrossRef]

13. Hao, H.; Yao, J.; Wu, Q.; Wei, Y.; Dai, M.; Iqbal, Z.; Wang, X.; Wang, Y.; Huang, L.; Chen, D.; et al. Microbiological toxicity of tilmicosin on human colonic microflora in chemostats. Regul. Toxicol. Pharmacol. 2015, 73, 201-208. [CrossRef] [PubMed]

14. Gautier-Bouchardon, A.V.; Reinhardt, A.K.; Kobisch, M.; Kempf, I. In vitro development of resistance to enrofloxacin, erythromycin, tylosin, tiamulin and oxytetracycline in Mycoplasma gallisepticum, Mycoplasma iowae and Mycoplasma synoviae. Vet. Microbiol. 2002, 88, 47-58. [CrossRef]

15. Wang, H.; Ren, L.; Yu, X.; Hu, J.; Chen, Y.; He, G.; Jiang, Q. Antibiotic residues in meat, milk and aquatic products in Shanghai and human exposure assessment. Food Control. 2017, 80, 217-225. [CrossRef]

16. Ministry of Agriculture. The Maximum Residue Limits of Veterinary Drugs in Animal Foods; No. 235 Bulletin; Ministry of Agriculture of the People's Republic of China: Beijng, China, 29 June 2008.

17. Council Regulation (EC) No 2821/98 of 17 December 1998 amending, as regards withdrawal of the authorisation of certain antibiotics, Directive 70/524/EEC concerning additives in feeding-stuffs. Off. J. Eur. Communities 1998, L351, 4-5.

18. Chebira, B.; Boultif, L.; Agabou, A.; Mekroud, A. Validation of a high performance liquid chromatography (HPLC) method to detect and quantify some antibiotics residues in honey. Adv. Anim. Vet. Sci. 2015, 3, 295-301. [CrossRef]

19. Jank, L.; Martins, M.T.; Arsand, J.B.; Campos Motta, T.M.; Hoff, R.B.; Barreto, F.; Pizzolato, T.M. High-throughput method for macrolides and lincosamides antibiotics residues analysis in milk and muscle using a simple liquid-liquid extraction technique and liquid chromatography-electrospray-tandem mass spectrometry analysis (LC-MS/MS). Talanta 2015, 144, 686-695. [CrossRef]

20. Yibar, A.; Özcan, A.; Karaca, M.Y. Determination of erythromycin, spiramycin, tilmicosin and tylosin in animal feedingstuffs by liquid chromatography-tandem mass spectrometry. Kafkas Üniversitesi Vet. Fakültesi Derg. 2014, 20, 439-444. [CrossRef]

21. Wang, Z.; Beier, R.C.; Shen, J. Immunoassays for the detection of macrocyclic lactones in food matrices-A review. TrAC-Trends Anal. Chem. 2017, 92, 42-61. [CrossRef]

22. Liu, A.; Anfossi, L.; Shen, L.; Li, C.; Wang, X. Non-competitive immunoassay for low-molecular-weight contaminant detection in food, feed and agricultural products: A mini-review. Trends Food Sci. Technol. 2018, 71, 181-187. [CrossRef]

23. Du, B.; Wen, F.; Guo, X.; Zheng, N.; Zhang, Y.; Li, S.; Zhao, S.; Liu, H.; Meng, L.; Xu, Q.; et al. Evaluation of an ELISA-based visualization microarray chip technique for the detection of veterinary antibiotics in milk. Food Control. 2019, 106, 106713. [CrossRef]

24. Li, M.; Hua, X.; Ma, M.; Liu, J.; Zhou, L.; Wang, M. Detecting clothianidin residues in environmental and agricultural samples using rapid, sensitive enzyme-linked immunosorbent assay and gold immunochromatographic assay. Sci. Total Environ. 2014, 499, 1-6. [CrossRef] [PubMed]

25. Zhang, J.K.; Liu, J.X.; Wang, L.L.; Chai, L.; Wang, J.P. Production of the monoclonal antibody against tylosin for immunoassay of macrolide antibiotics in milk. J. Environ. Sci. Health Part B-Pestic. 2012, 47, 876-882. [CrossRef]

26. Le, T.; He, H.; Niu, X.; Chen, Y.; Xu, J. Development of an immunochromatographic assay for detection of tylosin and tilmicosin in muscle, liver, fish and eggs. Food Agric. Immunol. 2013, 24, 467-480. [CrossRef]

27. Zhang, J.K.; Qi, Y.H.; Liu, J.X.; Wang, J.P. Heterologous immunoassay for screening macrolide antibiotics residues in milk based on the monoclonal antibody of tylosin. Food Agric. Immunol. 2013, 24, 419-431. [CrossRef]

28. Le, T.; Zhu, L.; Yang, X. A quantum dot-based immunoassay for screening of tylosin and tilmicosin in edible animal tissues. Food Addit. Contam. Part A-Chem. Anal. Control. Expo. Risk Assess. 2015, 32, 719-724. [CrossRef]

29. Yao, C.; Xu, Z.; Wang, H.; Zhu, F.; Luo, L.; Yang, J.; Sun, Y.; Lei, H.; Tian, Y.; Shen, Y. High affinity antibody based on a rationally designed hapten and development of a chemiluminescence enzyme immunoassay for quantification of Alternariol in fruit Juice, maize and flour. Food Chem. 2019, 283, 359-366. [CrossRef] 
30. Yao, C.; Yang, J.; Xu, Z.; Wang, H.; Lei, H.; Sun, Y.; Tian, Y.; Shen, Y. Indirect competitive enzyme-linked immunosorbent assay for detection of tylosin in milk and water samples. Chin. J. Anal. Chem. 2018, 46, 1275-1281. [CrossRef]

31. Chen, Z.J.; Fu, H.J.; Luo, L.; Sun, Y.M.; Yang, J.Y.; Zeng, D.P.; Shen, Y.D.; Xu, Z.L. Development of competitive indirect ELISAs with a flexible working range for the simple quantification of melatonin in medicinal foods. Anal. Methods 2017, 9, 1617-1626. [CrossRef]

32. Köhler, G.; Milstein, C. Continuous cultures of fused cells secreting antibody of predefined specificity. Nature 1975, 256, 495-497. [CrossRef] [PubMed]

33. Determination of Spiramycin, Pyrimidin, Oleandomycin, Tilmicosin, Eythromycin, And Tylosin in Milk and Milk Powder by Liquid Chromatography-Tandem Mass Spectrometry; GB/T 22988-2008; National Standards of the People's Republic of China: Shenzhen, China, December 2008.

34. Xu, Z.; Shen, Y.; Sun, Y.; Campbell, K.; Tian, Y.; Zhang, S.; Lei, H.; Jiang, Y. Novel hapten synthesis for antibody production and development of an enzyme-linked immunosorbent assay for determination of furaltadone metabolite 3-amino-5-morpholinomethyl-2-oxazolidinone (AMOZ). Talanta 2013, 103, 306-313. [CrossRef] [PubMed]

35. Lei, H.; Shen, Y.; Song, L.; Yang, J.; Chevallier, O.P.; Haughey, S.A.; Wang, H.; Sun, Y.; Elliott, C.T. Hapten synthesis and antibody production for the development of a melamine immunoassay. Anal. Chim. Acta 2010, 665, 84-90. [CrossRef] [PubMed]

36. Wang, F.; Cai, J.; Eremin, S.A.; Xiao, Z.; Shen, Y.; Tian, Y.; Xu, Z.; Yang, J.; Lei, H.; Sun, Y.; et al. Fluorescence Polarization Immunoassay for Alternaria Mycotoxin Tenuazonic Acid Detection and Molecular Modeling Studies of Antibody Recognition. Food Anal. Methods 2018, 11, 2455-2462. [CrossRef]

37. He, F.; Tian, Y.; Xu, Z.; Luo, L.; Yang, J.; Wang, H.; Sun, Y.; Du, Q.; Shen, Y. Development of an immunochromatographic assay as a screen for detection of total phthalate acid esters in cooking oil. J. Toxicol. Environ. Health-Part A-Curr. Issues 2018, 81, 80-88. [CrossRef]

38. Song, J.; Wang, R.M.; Wang, Y.Q.; Tang, Y.R.; Deng, A.P. Hapten design, modification and preparation of artificial antigens. Chin. J. Anal. Chem. 2010, 38, 1211-1218. [CrossRef]

39. Goodrow, M.H.; Hammock, B.D. Hapten design for compound-selective antibodies: ELISAS for environmentally deleterious small molecules. Anal. Chim. Acta 1998, 376, 83-91. [CrossRef]

40. Shen, Y.D.; Wang, Y.; Zhang, S.W.; Xiao, Z.L.; Sun, Y.M.; Bu, X.Z.; Gu, L.Q. Design and efficient synthesis of novel haptens and complete antigens for the AOZ, a toxic metabolite of furazolidone. Chin. Chem. Lett. 2007, 18, 1490-1492. [CrossRef]

41. Liu, F.; Chen, Z.; Shen, Y.; Sun, Y.; Yang, J.; Wang, H.; Xu, Z. Hapten synthesis and production of specific antibody against 3-amino-5-morpholinomethyl-2-oxazolidone for immunoassay without derivatisation. Food Agric. Immunol. 2018, 29, 332-345. [CrossRef]

42. He, F.; Zou, T.; Yang, J.; Wang, H.; Deng, L.; Tian, Y.; Xu, Z.; Sun, Y.; Lei, H.; Tan, X.; et al. Development of a skeleton-specific antibody and Au nanoparticle-based immunochromatographic sensor for simultaneous detection of various tadalafil adulterants in health food. Food Agric. Immunol. 2019, 30, 349-368. [CrossRef]

43. Paek, S.; Lee, S.; Cho, J.; Kim, Y. Development of Rapid One-Step Immunochromatographic Assay. Methods 2000, 22, 53-60. [CrossRef]

44. Wang, Z.; Yu, X.; Ma, L.; Liu, H.; Ding, S.; Wang, Z.; Zhang, X.; Shen, J.; Wen, K. Preparation of high affinity antibody for ribavirin with new haptens and residue analysis in chicken muscle, eggs and duck muscle. Food Addit. Contam. Part A 2018, 35, 1247-1256. [CrossRef]

45. Liu, A. Effects of pretreatment of food samples on residues of veterinary drug residues. Mod. Food 2017, 2017, 49-50. [CrossRef]

(C) 2019 by the authors. Licensee MDPI, Basel, Switzerland. This article is an open access article distributed under the terms and conditions of the Creative Commons Attribution (CC BY) license (http://creativecommons.org/licenses/by/4.0/). 